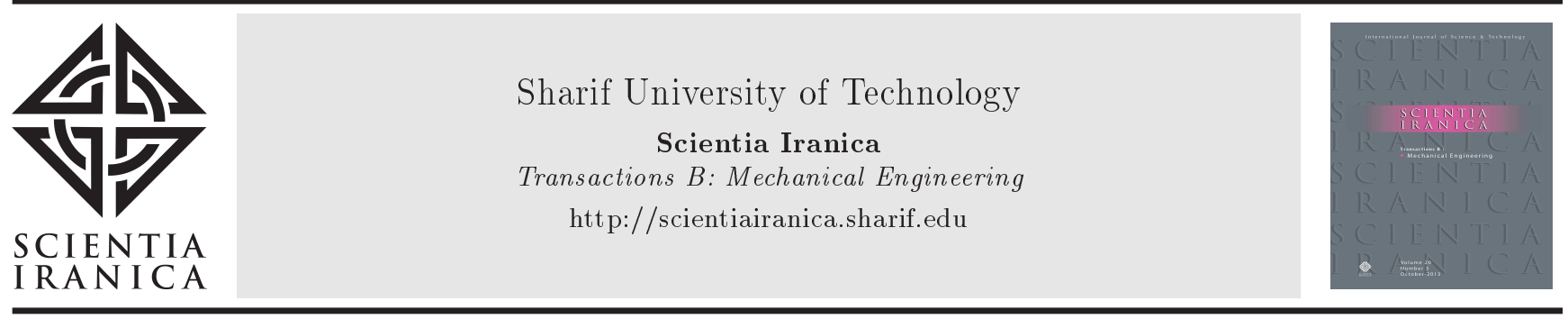

\title{
Heat transfer correlation for a cross-flow jet impingement on a protruded surface
}

\author{
S. Rout, A. Mukherjee, and A.K. Barik* \\ College of Engineering and Technology (CET), Bhubaneswar-751029, Odisha, India.
}

Received 20 October 2017; received in revised form 26 April 2018; accepted 26 January 2019

\section{KEYWORDS}

$\mathrm{Al}_{2} \mathrm{O}_{3}$-water

nanofluid;

Cross-flow jet;

Surface protrusion;

Turbulence model;

Nusselt number.

\begin{abstract}
This study proposed the heat transfer correlation for a surface fitted with rectangular ribs by solving the continuity, momentum, energy, and turbulence equations by the finite volume approach. Extensive computations were performed to modify both the duct Reynolds number $\left(\operatorname{Re}_{D h, d u c t}\right)$ and the nozzle Reynolds number $\left(\operatorname{Re}_{D h, n z}\right)$ in the range of $6,000-20,000$. The volume fraction $(\phi)$ and the Prandtl number $(\operatorname{Pr})$ of the nanofluid varied in the range of 0 to $5 \%$ and 7.288 to 9.92 , respectively. The number of protrusions $(n)$ varied from 1 to 4 . The data collected from numerical experimentation were regressed nonlinearly using Levenberg and Marquest (L-M) method to obtain an empirical correlation for the Nusselt number. The Nusselt number predicted from the correlation was compared with its value obtained from the computations. Close agreement between the predicted and computed Nusselt numbers was observed. In terms of heat transfer augmentation, the duct Reynolds number, the nozzle Reynolds number, and the volume fraction of nanofluid were found to be some of the significant influencing parameters in heat transfer.
\end{abstract}

(C) 2020 Sharif University of Technology. All rights reserved.

\section{Introduction}

The effective elimination of heat from a heated surface, especially from electronic processors, is becoming popular and demanding due to the shift in the paradigm of technology from macro to mini sizes. A continuous reduction in size, the increasing demand for faster operating speed, and the longer durability of devices further necessitate the invention of new technologies and methods for effective cooling so as to safeguard the devices and perform a hassle-free operation. In this context, several new methodologies have been tried. The innovative design of thermal equipment and the use of high heat transfer fluids are a few examples of

*. Corresponding author. Tel.: +91674 2386075 ; Fax: + 916742386182

E-mail addresses: ashokbarik.mech@gmail.com and ashok_iit@hotmail.com (A.K.Barik)

doi: $10.24200 /$ sci.2019.4985.1029 attaining a higher degree of heat dissipation. Recently, nanofluids have been extensively used for augmenting heat transfer in micro-sized devices (i.e., micro channels, microelectronic systems, and MEMS) to macrosized devices (i.e., heat exchangers, power plants, and solar applications). Nanofluids have been found to be widely applicable by different researchers since their first use in modern technology by Choi [1]. Generally, the water suspended with solid metallic oxides possesses higher thermal conductivity than the usual pure water and ethylene glycol. Thus, the enhancement of heat transfer by these fluids is greater than that by water due to their better thermal capability [2-6]. A number of researchers have developed empirical correlations to look into the thermo-hydraulic characteristics of nanofluids in both the force and free convection regimes. An empirical correlation for Nusselt number was proposed by Pak and Cho [7] using two different water-soluble nanofluids (i.e., $\mathrm{Al}_{2} \mathrm{O}_{3}$ - and $\mathrm{TiO}_{2}$-water) for a turbulent bend tube. It was demonstrated that Re and $\phi$ of the nanofluid influenced the heat transfer 
significantly. Wen and Ding [8] studied the heat transfer of nanofluids experimentally, which is higher than that of water, and obtained similar observations. Empirical correlations for heat transfer of $\mathrm{CuO}, \mathrm{TiO}_{2}$, and $\mathrm{Al}_{2} \mathrm{O}_{3}$ nanofluids in both laminar and turbulent regimes were developed by $\mathrm{Li}$ et al. [9]. For Cuowater nanofluid turbulent flow in a pipe, Xuan and Lee [10] developed an empirical correlation for Nusselt number in terms of the Reynolds number, Prandtl number and Peclet number, and volume fraction of the nanoparticle. Vijjha et al. [11] proposed another correlation for Nusselt number of $\mathrm{Al}_{2} \mathrm{O}_{3}$ and $\mathrm{CuO}$ nanofluids in a turbulent regime. Moreover, Suresh et al. [12] obtained the fully developed heat transfer correlation for a laminar flow of a hybrid-class nanofluid (i.e., $\mathrm{Al}_{2} \mathrm{O}_{3}-\mathrm{Cu}$ /water) in a tube subjected to uniform heat flux. Xuan and Roetzel [13] included the effect of thermal dispersion of nanoparticles in their heat transfer correlation. For $\mathrm{CuO}$ nanoparticle dispersed in the oil, the heat transfer correlation was also developed by Raji et al. [14] in round and flattened tubes. Heat transfer correlation for $\mathrm{Al}_{2} \mathrm{O}_{3}$-water nanofluid flow in a microchannel was proposed by Zhang et al. [15]. Using the regression analysis of the data, Jafarimoghaddam and Aberoumand [16] obtained a heat transfer correlation for $\mathrm{Cu}$ /ethylene glycol nanofluid flowing in a concentric annular tube applied to a uniform wall heat flux. The empirical correlation was found to have limited applications since both the Reynolds number ( $R e \leq 160)$ and the nanofluid volume fraction $(0.011$ $\leq \phi \leq 0.171$ ) were in narrow ranges. Sajadi and Kazemi [17] developed a correlation for heat transfer in the turbulent regime of $\mathrm{TiO}_{2}$-water nanofluid from their experimental data. For $\mathrm{TiO}_{2}$-water nanofluid, empirical correlations for heat transfer and fluid friction were proposed by Duangthongsuk and Wongwises [18] and Abbasian Arani and Amani [19]. Through a series of careful experimental observations, Anoop et al. [20] proposed a heat correlation for a laminar flow $(500 \leq \operatorname{Re} \leq 2,000)$ of alumina-water nanofluid in the developing region $(50<X / D<200)$. Their empirical correlation suggests a higher level of heat transfer with smaller particles than the larger ones. Moreover, Lattice Boltzmann Method (LBM) was applied by Sheikholeslami et al. [21] and Nemati et al. [22] to study the MHD natural convection of nanofluid with different configurations. It was concluded that $\phi$ influenced heat transfer, whereas the magnetic field suppressed the heat transfer enhancement due to the opposing action of the Lorentz force to the motion of fluid. A numerical study was carried out by Khorasanizadeh et al. [23] for a rectangular cavity with a conductive baffle placed at the bottom by implementing the finite volume method. They observed that, at a low Rayleigh number, the mean Nusselt number decreased by displacing the baffle toward the center. They claimed that the conduction heat transfer, which is dominant at the low Rayleigh number, was reduced and convection took over the conduction as the baffle moved to the center. Wei et al. [24] developed a model to account for the nanofluid thermal conductivity through the fractal analysis. Their developed model is also validated with the experimental results of the effective thermal conductivity of the nanofluid. Sivashi et al. [25] investigated the effect of $\phi$, the number and length of the porous fins attached to one of the walls of a twodimensional rectangular domain on heat transfer from the heated surface using porous and solid fins. They obtained better heat conduction for porous fins than solid/non-porous fins, and concluded that heat transfer with porous fins was higher than that with non-porous fins. Moreover, their numerical study showed that a higher level of heat transfer enhancement could be obtained at high Darcy number than at low Darcy number. At low Darcy number, the convection weakens and, thus, the heat transfer reduces.

Recently, the authors [26] studied entropy generation in the case of heated surface by impinging nanofluid on trapezoidal protrusions using a similar duct. Based on the previous literature, many studies on nanofluid have been carried out to use nanofluid for heat transfer augmentation in various engineering applications. Moreover, a large number of heat transfer correlations exist for nanofluid as an alternative fluid in the open literature. However, according to the literature survey, there exists no such empirical correlation for a protruded surface with jet impingement onto it. Therefore, the present study aims to develop an empirical correlation for Nusselt number of the protruded surface with the cross-flow jet impingement. Rigorous and careful numerical simulations are carried out in a commercial Computational Fluid Dynamics (CFD) solver to capture the data and, then, a nonlinear regression analysis is conducted to develop a heat transfer correlation.

\section{Numerical modeling}

\subsection{Model description with grid setup}

Figure 1 shows the geometrical dimensions of the physical model with different boundary conditions. A constant temperature (i.e., $353 \mathrm{~K}$ ) was imposed on the marked (with a dotted rectangle) region of the bottom wall, as shown in Figure 2(a). Rectangular protrusions were installed on the heated surface, maintaining an inter-protrusion distance of $0.016 \mathrm{~mm}$. All walls are adiabatic, except the heated one.

A stream of $\mathrm{Al}_{2} \mathrm{O}_{3}$-water nanofluid is allowed to flow through the inlet at a uniform velocity. Moreover, another stream of nanofluid emanates from the nozzle exit and mixes with the flow coming from the duct inlet and, thus, forms a cross-flow with the jet flow. 


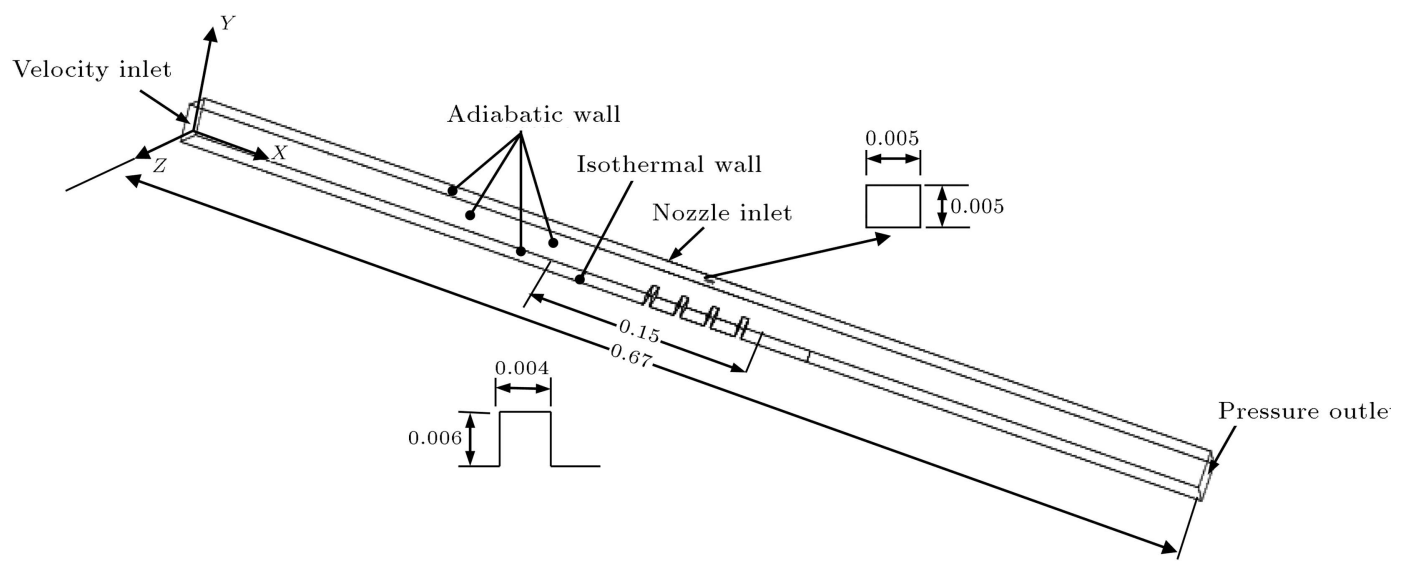

Figure 1. Geometrical dimension with boundary conditions (all dimensions are in $\mathrm{m}$ ).

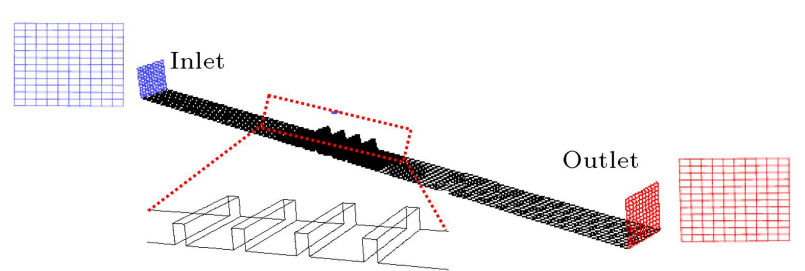

(a)

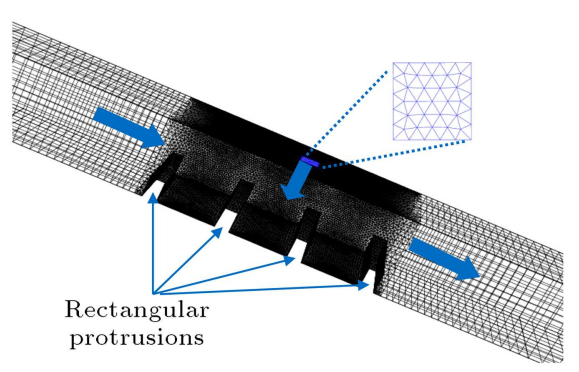

(b)

Figure 2. (a) Computational mesh and (b) enlarged illustration of mesh around protrusions.

The cross flow is believed to improve the mixing of cold and hot streams in close proximity to the heated wall. Thus, a higher heat transfer rate with this type of arrangement is expected. At upstream of the heated surface, the duct is given an extra length (i.e., $X / D h=10)$ in order to ensure a fully developed flow (hydro-dynamically) on the heated surface. The grid arrangement at the inlet, outlet, and bottom wall is depicted in Figure 2(a). Figure 2(b) shows an enlarged and cutaway illustration of the grid around the protrusions.

\subsection{Different properties of nanofluid}

The nanofluid is considered as single phased and homogenous because (i) the particles are very small in diameter (i.e., $100 \mathrm{~nm}$ [27]) and (ii) are thoroughly mixed in water. The thermo-physical properties of alumina nanoparticle and water (i.e., base fluid) at $300 \mathrm{~K}$ and $101.325 \mathrm{kN} / \mathrm{m}^{2}$ are shown in Table 1.

\subsubsection{Density}

Eq. (1) shows a mathematical relationship among the density of the nanofluid, nanoparticle density, and volume fraction. Eq. (1) is used [27-29] to calculate the density of the nanofluid. Thus, the nanofluid density can be calculated through this equation, as shown below:

$$
\rho_{n f}=(1-\phi) \rho_{b f}+\phi \rho_{p} .
$$

\subsubsection{Specific heat}

The specific heat of the nanofluid is computed through Eq. (2) [7,27, and 29]:

$$
c_{n f}=(1-\phi) c_{b f}+\phi c_{p} .
$$

\subsubsection{Dynamic viscosity}

The dynamic viscosity is computed through Eq. (3), which is similar to the equation proposed by Maiga et al. [28] through the curve fitting of the data given in [30-31]. Since the effects of the physical phenomena

Table 1. Thermo-physical properties [27].

\begin{tabular}{lcc}
\hline Properties & $\begin{array}{c}\mathbf{A l}_{\mathbf{2}} \mathbf{O}_{\mathbf{3}^{-}} \\
\text {nanoparicles }(\boldsymbol{p})\end{array}$ & Water $(\boldsymbol{b} \boldsymbol{f})$ \\
\hline Density, $\rho\left(\mathrm{kg} / \mathrm{m}^{3}\right)$ & 3880 & 998.2 \\
Thermal conductivity, $k(\mathrm{~W} / \mathrm{mK})$ & 36 & 0.597 \\
Sp. heat, $c(\mathrm{~J} / \mathrm{kgK})$ & 773 & 4182 \\
Viscosity $(\mathrm{kg} / \mathrm{ms})$ & - & $9.93 \times 10^{-4}$ \\
\hline
\end{tabular}


such as the thermophoresis, the Brownian motion, and the velocity slip are neglected, Eq. (3) is selected for calculating the viscosity of the nanofluid:

$$
\mu_{r}=\frac{\mu_{n f}}{\mu_{b f}}=123 \phi^{2}+7.3 \phi+1
$$

\subsubsection{Thermal conductivity}

The nanofluid thermal conductivity is calculated through Eq. (4):

$$
k_{r}=\frac{k_{n f}}{k_{b f}}=4.97 \phi^{2}+2.72 \phi+1 .
$$

Maiga et al. [28] developed the above equation (Eq. (4)) based on the experimental data of Wang et al. [30] through curve fitting. According to Maiga et al. [28], Eq. (4) is used to predict a lower thermal conductivity rate of the nanofluid since it is assumed that all the nanoparticles suspended in the base fluid are spherical. However, this assumption may not be true in reality. Since Eq. (4) is quite a simple model and can be easily implemented in numerical computations, the proposed model in our study is preferred.

\section{Formulation of the computational study}

\subsection{Governing equations}

The continuity, momentum, energy, turbulent kinetic energy, and its dissipation rate equations were solved iteratively in a 3D domain using finite volume method. The nanofluid is assumed to be incompressible and single phased. The physical properties such as thermal conductivity $\left(k_{n f}\right)$, dynamic viscosity $\left(\mu_{n f}\right)$, and specific heat $\left(c_{p, n f}\right)$ are kept constant throughout the entire computational domain. Nanoparticles are very fine in size and well mixed in water. The diameter of the nanoparticle for practical applications is usually less than $100 \mathrm{~nm}$. Thus, suspension behaves like a single-phase continuum [32-33]. Since the proposed objective is to develop an empirical relation in terms of the independent variables, the thermohydraulic properties are kept constant; otherwise, the number of simulations may increase due to excessive complexity and error in the correlation. Of note, velocity slip between the continuous (i.e., water) and discrete (i.e., nanoparticles) phases is neglected, thus establishing a thermal equilibrium between them. Moreover, particle diffusion has been ignored in the present case. Different equations relevant to the present study are written as follows:

$$
\begin{aligned}
& \frac{\partial U_{i}}{\partial x_{i}}=0 \\
& \rho_{n f} U_{j} \frac{\partial U_{i}}{\partial x_{j}}=-\frac{\partial P}{\partial x_{i}}+\frac{\partial}{\partial x_{j}}\left(2 \mu_{n f} S_{i j}-\rho_{n f} \overline{u_{i}^{\prime} u_{j}^{\prime}}\right), \\
& \rho_{n f} U_{j} \frac{\partial T}{\partial x_{j}}=\frac{\partial}{\partial x_{j}}\left(\frac{\lambda_{n f}}{c_{p, n f}} \frac{\partial T}{\partial x_{j}}-\rho_{n f} \overline{T^{\prime} u_{j}}\right) .
\end{aligned}
$$

The rate of the mean strain $S_{i j}$ is defined as follows:

$$
S_{i j}=\frac{1}{2}\left(\frac{\partial U_{i}}{\partial x_{j}}+\frac{\partial U_{j}}{\partial x_{i}}\right) .
$$

The subscripts $i$ and $j$ are the notations used to represent a tensor, whereas $n f$ represents the nanofluid. $\lambda, \mu$, and $c$ represent the thermal conductivity, the dynamic viscosity, and the specific heat, respectively. Since the flow in the duct is turbulent, the mean pressure, temperature, and velocities are denoted by $P, T$, and $U_{i}$, respectively, whereas the fluctuating temperature and velocity are denoted by $T^{\prime}$ and $u_{i}^{\prime}$. Two physical quantities such as turbulent Reynolds stress $\left(-\rho_{n f} \overline{u_{i}^{\prime} u_{j}^{\prime}}\right)$ and turbulent heat flux $\left(-\rho_{n f} \overline{u_{i}^{\prime} T^{\prime}}\right)$ have been obtained due to the averaging of the momentum and energy equations. These two quantities are modeled using Eqs. (9) and (10).

$$
\begin{aligned}
& -\rho_{n f} \overline{u_{i}^{\prime} u_{j}^{\prime}}=2 \mu_{t} S_{i j}-\frac{2}{3} \rho_{n f} k \delta_{i j}, \\
& \delta_{i j}=0(i \neq j), \\
& -\rho_{n f} \overline{u_{i}^{\prime} T^{\prime}}=\frac{\mu_{t}}{\operatorname{Pr}_{t}} \frac{\partial \bar{T}}{\partial x_{i}} .
\end{aligned}
$$

In Eq. (9), $k, \mu_{t}$, and $\delta_{i j}$ represent the turbulent kinetic energy, the eddy viscosity, and Kronecker delta $\left(\delta_{i j}=\right.$ 1 , if $i=j$; else, $\delta_{i j}=0$ if $i \neq j$ ), respectively. The turbulent Prandtl number in Eq. (10) is kept constant $\left(\operatorname{Pr}_{t}=0.85\right)$. Since a series of protrusions were installed on the bottom hot surface, the flow recirculation behind the protrusions was inevitable. Thus, it was recommended that the SST $k-\omega$ turbulence model [34] be used for such flows with intense recirculation. The kinetic energy $(k)$ and its dissipation rate $(\omega)$ for a turbulent flow are given as follows:

$$
\begin{gathered}
\frac{\partial}{\partial x_{i}}\left(\rho_{n f} k u_{i}\right)=\frac{\partial}{\partial x_{j}}\left[\left(\mu_{n f}+\frac{\mu_{t}}{\sigma_{k}}\right) \frac{\partial k}{\partial x_{j}}\right] \\
+\min \left(P_{k}, 10 \rho_{n f} \beta^{*} k \omega\right)-\rho_{n f} \beta^{*} k \omega \\
\frac{\partial}{\partial x_{i}}\left(\rho_{n f} \omega u_{i}\right)=\frac{\partial}{\partial x_{j}}\left[\left(\mu_{n f}+\frac{\mu_{t}}{\sigma_{k}}\right) \frac{\partial \omega}{\partial x_{j}}\right] \\
+\frac{\alpha \omega}{k} P_{k}-\rho_{n f} \beta \omega^{2} \\
+2\left(1-F_{1}\right) \frac{\rho_{n f} \sigma_{\omega, 2}}{\omega} \frac{\partial k}{\partial x_{j}} \frac{\partial \omega}{\partial x_{j}} .
\end{gathered}
$$

The turbulent viscosity in $\operatorname{SST} k-\omega$ is defined as:

$$
\mu_{t}=\rho_{n f} \frac{k}{\omega} \frac{1}{\max \left(\frac{1}{\alpha^{*}}, \frac{S F_{2}}{a_{1} \omega}\right)},
$$

where: 


$$
\begin{aligned}
& S=\sqrt{2 S_{i j} S_{i j}}, \quad a_{1}=0.31, \\
& F_{1}=\tanh \left(\phi_{1}^{4}\right), \quad F_{2}=\tanh \left(\phi_{2}^{2}\right), \\
& \phi_{1}=\min \left[\max \left(\frac{\sqrt{k}}{0.09 \omega y}, \frac{500 \mu_{n f}}{\rho_{n f} y^{2} \omega}\right), \frac{4 \rho_{n f} k}{\sigma_{\omega, 2} D_{\omega}^{+} y^{2}}\right],
\end{aligned}
$$

and

$$
\phi_{2}=\max \left[2 \frac{\sqrt{k}}{0.09 \omega y}, \frac{500 \mu_{n f}}{\rho_{n f} y^{2} \omega}\right]
$$

respectively. The positive cross-diffusion part is given as:

$$
D_{\omega}^{+}=\max \left[\frac{2 \rho_{n f}}{\sigma_{\omega, 2} \omega} \frac{\partial k}{\partial x_{j}} \frac{\partial \omega}{\partial x_{j}}, 10^{-10}\right],
$$

and the production of Turbulent Kinetic Energy (TKE) that appears in both Eqs. (11) and (12) is defined as $P_{k}=-\rho_{n f} \overline{u_{i}^{\prime} u_{j}^{\prime}} \frac{\partial u_{i}}{\partial x_{i}}$. In the SST $k-\omega$ model, the viscosity is damped through a damping coefficient $\left(\alpha^{*}\right)$, which makes this model a better option over the standard $k-\varepsilon$ model when a strong flow recirculation appears in the computational domain.

$$
\alpha^{*}=\alpha_{\infty}^{*}\left(\frac{\alpha_{0}^{*}+\operatorname{Re}_{t} / R_{k}}{1+\operatorname{Re}_{t} / R_{k}}\right) .
$$

In Eq. (13), $\alpha_{0}^{*}$ and $\operatorname{Re}_{t}$ are defined as $\alpha_{0}^{*}=\beta_{i} / 3$ and $\operatorname{Re}_{t}=\left(\rho_{n f} k\right) / \mu_{n f} \omega$. Since the flow is assumed to be incompressible, $\beta^{*}$ in Eq. (11) is equal to $\beta_{i}^{*}$, which is defined as follows:

$$
\beta_{i}^{*}=\beta_{\infty}^{*}\left(\frac{4 / 15+\left(R e_{t} / R_{\beta}\right)^{4}}{1+\left(R e_{t} / R_{\beta}\right)^{4}}\right)
$$

Different constants used in SST $k-\omega$ model are as follows:

$$
\begin{aligned}
& \alpha_{\infty}^{*}=1, \quad \beta_{\infty}^{*}=0.09, \quad \beta_{i}=0.072 \\
& \sigma_{k, 1}=1.176, \quad \sigma_{\omega, 1}=2, \quad \sigma_{k, 2}=1 \\
& \sigma_{\omega, 2}=1.168, \quad R_{k}=6, \quad R_{\beta}=8 .
\end{aligned}
$$

\subsection{Boundary conditions}

The numerical boundary conditions are illustrated in Figure 1. Both the duct inlets are considered as velocity inlet in the commercial ANSYS 15 software. The bottom surface with protrusions is exposed to a constant temperature, and the rest of the bounding surfaces of the duct are adiabatic. The flow from the duct exit is issued in the atmospheric condition, where pressure is usually atmospheric. Therefore, the pressure outlet boundary condition may be a natural choice for the duct exit. The no-slip, adiabatic, constant temperature and constant velocity boundary conditions on different surfaces [35] are given as follows:

At insulated walls:

$$
\frac{\partial T}{\partial x}=\frac{\partial T}{\partial y}=\frac{\partial T}{\partial z}=0, \quad \text { and } \quad u=v=w=0 .
$$

At constant temperature wall:

$$
T=T_{w}=353 K, \quad \text { and } \quad u=v=w=0 .
$$

At inlet of the duct:

$$
T=T_{\infty}=300 \mathrm{~K}, \quad u=u_{\text {in }} .
$$

At inlet of the nozzle:

$$
T=T_{\infty}=300 K, \quad v=-v_{i n} .
$$

Here, $u, v$, and $w$ are the velocity components in the $x, y$, and $z$ directions, respectively.

At outlet:

$$
T=T_{\infty}, \quad \text { and } \quad p=p_{\infty} .
$$

As the iterative solution progresses, the variables close to the wall cells are linked to the value of those variables on the wall via the standard wall function [36].

The logarithmic wall law is written as follows:

$$
\begin{aligned}
& \frac{U_{p} k_{p}{ }^{1 / 2} c_{\mu}{ }^{1 / 4}}{\tau_{w} / \rho_{n f}}=\frac{1}{\kappa} \ln \left(E y^{*}\right), \\
& y^{*}=\frac{\rho_{n f} k_{p}{ }^{1 / 2} c_{\mu}{ }^{1 / 4} y_{p}}{\mu_{n f}} .
\end{aligned}
$$

The empirical constant $(E)$ and von Karman constant $(\kappa)$ in Eq. (20) are 9.793 and 0.418 , respectively. $U_{p}$ and $y^{*}$ represent the fluid mean velocity at the point ' $p$ ' and the non-dimensional distance between the wall and cell-centroid of the first cell near the wall. At the nozzle inlet and duct inlet, the turbulent intensity is required to be determined at the beginning of the solution, which is computed as $I=0.016 \mathrm{Re}^{-1 / 8}$, where $\operatorname{Re}=\operatorname{Re}_{D h, d u c t}$ and $\operatorname{Re}=\operatorname{Re}_{D h, n z}$, respectively.

\subsection{Procedure for the numerical solution}

Eqs. (5)-(7) and (11)-(12) have been solved iteratively in the finite volume framework of ANSYS-Fluent 16.0 using the boundary conditions, as mentioned in Section 3.2. The 2nd-order upwind and the central difference schemes have been employed to discretize the advection and diffusion terms in momentum and energy equations. The discretization of the differential equations yields algebraic equations that are solved to obtain the desired solution variables using the whole field residual method of ANSYS-Fluent 16.0. The 
pressure correction is achieved by the SIMPLE method. The iterative solutions for mass, momentum, and turbulence equations are considered to be converged if the residuals fall below $10^{-4}$. However, the convergence criterion for energy equation is set to $10^{-7}$. The SST $k-\omega$ model has been preferred over the $k-\varepsilon$ model owing to a strong flow recirculation behind the protrusions. Moreover, the near-wall region in SST $k-\omega$ model is resolved by using the blending function $\left(F_{1}\right.$ and $\left.F_{2}\right)$ and the cross diffusion term, whereas the far-field region is resolved by the $k-\varepsilon$ model. The turbulent jet impingement heat transfer has been studied by a number of scholars [37-39] using SST $k-\omega$ model.

\section{Validation}

The open literature on convection heat transfer by a cross-flow jet using nanofluid as a coolant is very limited in scope. However, many studies have investigated the heat transfer characteristics of a pipe carrying nanofluid as a coolant. Therefore, the authors have validated the present numerical methodology based on the results of Pak and Cho [7] and Maiga et al. [27]. For validation, a circular tube of diameter $0.01066 \mathrm{~m}$ and length $4.8 \mathrm{~m}$ was considered. The hydrodynamic entry length of $X / D_{h}=157$ was considered so as to obtain a fully developed flow at the entrance of the heated region $\left(X / D_{h}=330\right)$ of the pipe. A constant wall flux was applied to the heating zone of the pipe. The heat flux was calculated from the data given in [7]. Since the mean flow was turbulent, $k-\omega$ turbulence model was incorporated into the numerical models to obtain the turbulent quantities. Figure 3(a) shows the comparison between the present numerical results and the experimental results of [27]. Moreover, the present computational results were also validated based on the general-purpose heat transfer correlation given by Maiga et al. [27].

A straight pipe subjected to a uniform wall heat flux is considered for the present validation. The results

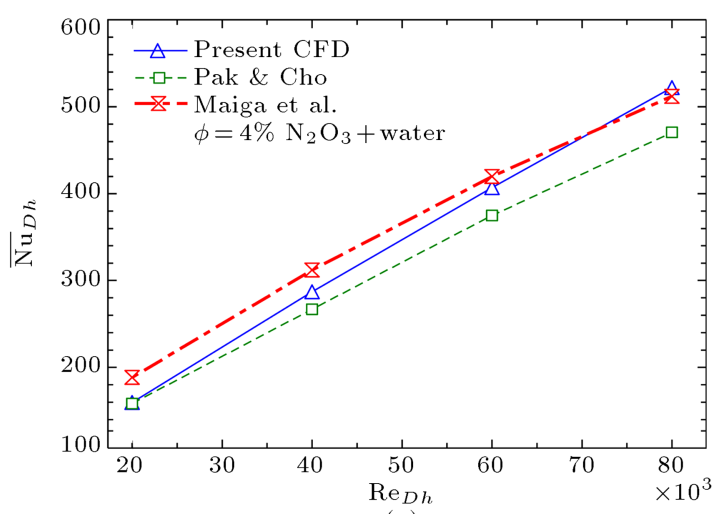

(a) of the present numerical methodology are in agreement with those of [27], limiting the error within 5\%, which is acceptable for engineering applications. Since this study has used a cross-flow jet to impinge the fluid normal onto the main flow (see Figure 2(b)), it is always helpful to validate the numerical schemes with the studies involving jet impingement. Moreover, the flow behavior for an impinging jet is quite different from a simple close conduct flow. Hence, a separate case of validation is carried out with Sun et al. For this validation, a circular nozzle (diameter $=3 \mathrm{~mm}$ ) was employed to impinge $\mathrm{CuO}$-water nanofluid on a target plate kept at $6 \mathrm{~mm}$ apart from the nozzle exit. In our numerical validation, the diameter of the target plate was taken to be 40 times greater than the diameter of the nozzle so as to keep the flow recirculation at a minimum level. The thermo-hydraulic properties of the nanofluid were derived from [40]. Figure 3(b) shows the experimental results of Sun et al. and the numerical results.

The Nusselt number computed through the present numerical scheme is in good agreement with the results given in [40].

\section{Results and discussion}

\subsection{Grid sensitivity test}

Figure 4 shows the grid sensitivity test. Initially, the

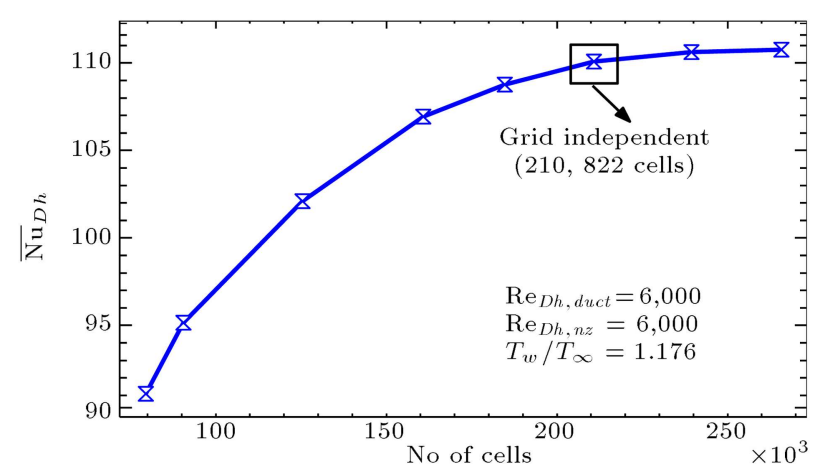

Figure 4. Variation of $\overline{\mathrm{Nu}}_{D h, \text { duct }}$ with number of cells.

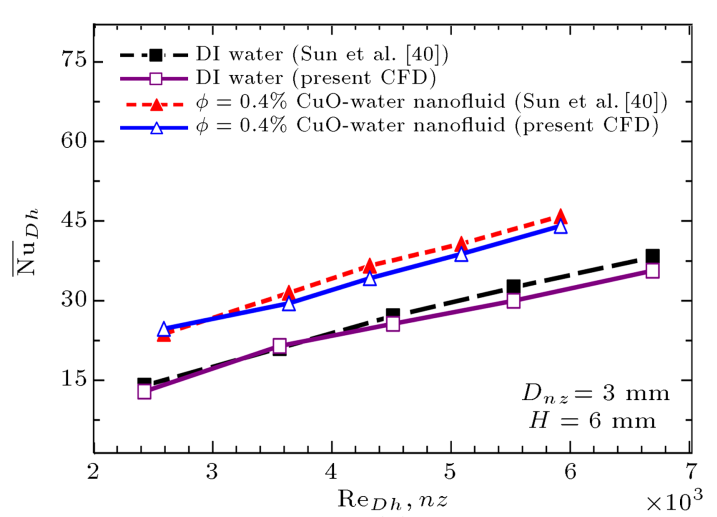

(b)

Figure 3. Variations of (a) $\overline{\mathrm{Nu}}_{D h}$ vs $\operatorname{Re}_{D h}$ and (b) $\overline{\mathrm{Nu}}_{D h}$ vs $\operatorname{Re}_{D h, n z}$ 
computational domain is meshed with the coarseness of cells $(79,490$ cells $)$, and the average Nusselt number is found to be 90 . To incorporate a finer mesh, the number of cells gradually increases in the computational domain until the solution variables show no or negligible change. As can be observed in Figure 4, the rate of an increase in Nusselt number diminishes with the number of cells. According to Figure 4, an increment in the Nusselt number is very low (i.e., $0.45 \%$ ) as the number of cells increases from 210,822 to 245,690 . Beyond 145,690 cells, an increment in the Nusselt number is even less significant. Therefore, the computational domain is considered to be grid independent at 210,822 cells. For further analysis, the computational domain is deployed with the above-mentioned number of cells. The present grid-independent study is carried out with four surface protrusions with $\phi=5 \%$.

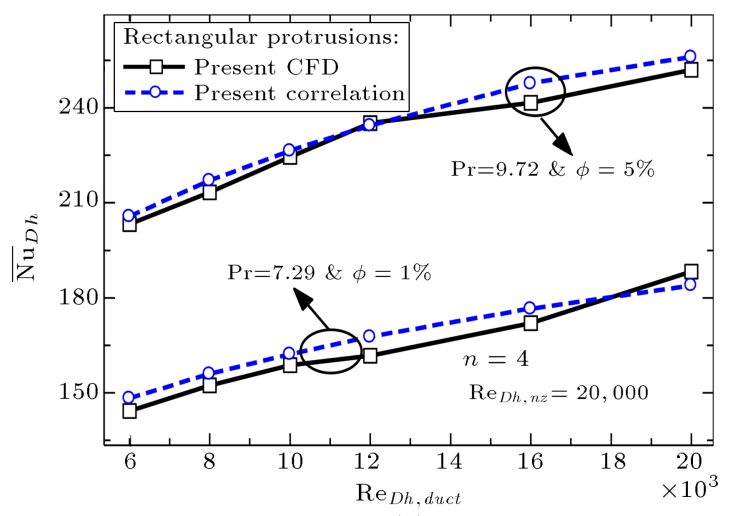

(a)

\subsection{Effects of $\operatorname{Re}_{D h, \text { duct }}$ and $\operatorname{Re}_{D h, n z}$ on heat transfer}

The effects of both the nozzle and duct Reynolds number on heat transfer from the protruded surface are illustrated in Figure 5(a) and (b). It is noticed that Nusselt number $\left(\overline{\mathrm{Nu}}_{D h}\right)$ increases with the duct Reynolds number $\left(\operatorname{Re}_{D h, d u c t}\right)$. This observation is quite obvious because of an enhanced heat dissipation rate at high $\operatorname{Re}_{D h, \text { duct }}$. The increased $\operatorname{Re}_{D h, \text { duct }}$ improves the convection heat transfer due to the occurrence of flow recirculation in between the protrusions (i.e., inter-protrusion gaps). The inter-protrusion recirculation imparts rigorous mixing of the hot and cold fluid streams, thereby breaking the thermal boundary layer near the hot wall. For $n=4$, the velocity vector and contour plots (flooded with color code) are shown in Figure 6(a) and (b), respectively. According to the

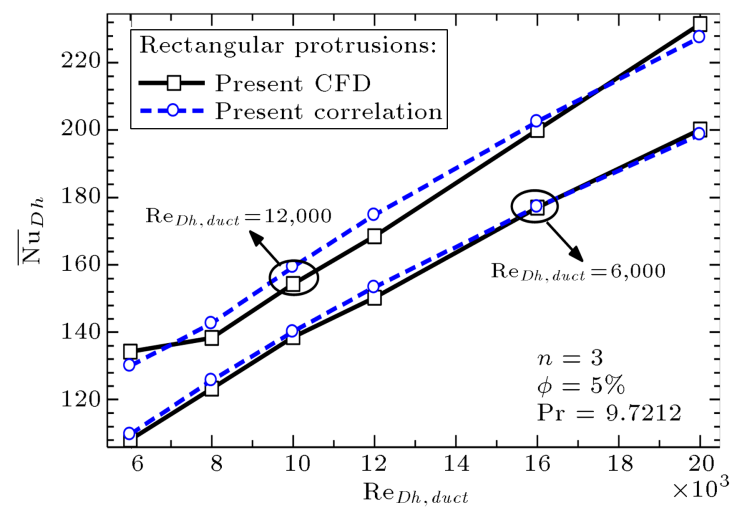

(b)

Figure 5. Variations of (a) $\overline{\mathrm{Nu}}$ vs $\operatorname{Re}_{D h, \text { duct }}$ and (b) $\overline{\mathrm{Nu}}$ vs $\operatorname{Re}_{D h, n z}$.

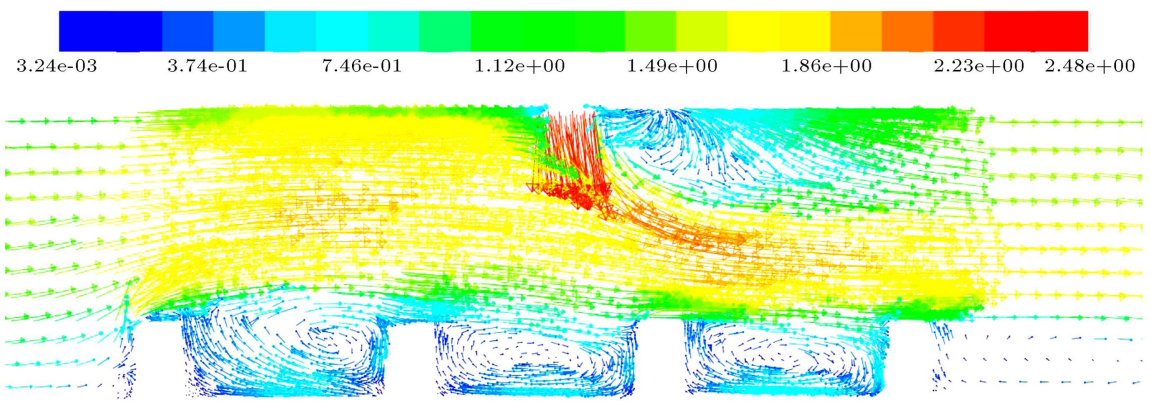

(a)

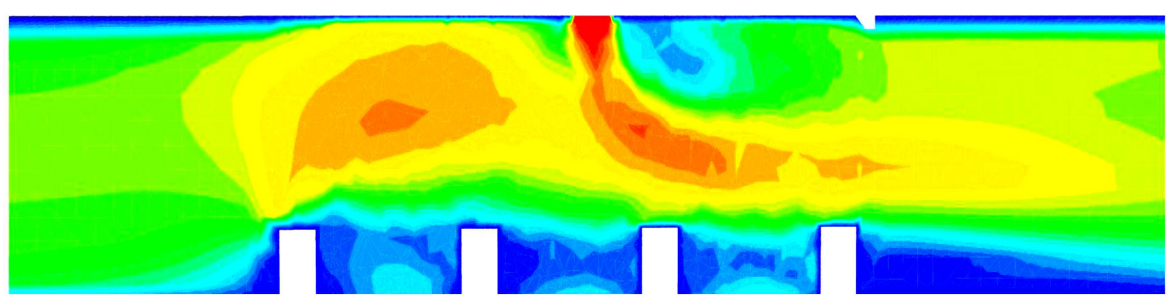

(b)

Figure 6. Expanded and cutaway views of (a) velocity vector and (b) contours of velocity vector for $\phi=5 \%$, $\operatorname{Re}_{D h, d u c t}=20,000, \operatorname{Re}_{D h, n z}=8,000$, and $n=4$. 
velocity vector plot, there exists a clockwise recirculation in the inter-protrusion valleys, which could bring the cold bulk fluid into the valleys and carry heat along with it. The thermal boundary layer, which is expected to develop behind each protrusion, is broken up due to the recirculation so as to improve the heat transfer from the hot surface to the bulk fluid. Moreover, the local velocity increases as the flow approaches the first protrusion due to a reduction in the flow area. The flow accelerates near the first protrusion and decelerates as it further approaches other protrusions and mixes with flow coming from the jet exit (see Figure 6(b)). For $\phi=5 \%, n=4$, and $\operatorname{Pr}=9.72$, the Nusselt number has improved by $24.7 \%$ as increases from 6,000 to 20,000 , as shown in Figure 5(a). Since the Nusselt number is the function of both flow and geometric variables, it is expressed as $\bar{N} u_{D h}=f\left(\operatorname{Re}_{D h, d u c t}, \operatorname{Re}_{D h, n z}, \operatorname{Pr}, \phi, n\right)$.

A general heat transfer correlation equation was developed by considering each of the independent parameters through a non-linear regression analysis based on the Levenberg-Marquardt (L-M) algorithm in polymath software. Finite volume method of ANSYS Fluent 16 was implemented to carry out extensive numerical computations to collect data for the Nusselt number by modifying each of the independent parameters. User-defined functions were formulated by dependent variables and unknown correlation coefficients. The square of the errors arising from CFD and predicted values were minimized iteratively through the L-M algorithm so as to achieve suitable correlation coefficients. It is worth mentioning that the total number of CFD data used to develop the present correlation is $576(6 \times 6 \times 4 \times 4)$. The correlation developed using the above-discussed method is written as follows:

$$
\begin{aligned}
\overline{\mathrm{Nu}}_{D h}= & 1.44 \operatorname{Re}_{D h, \text { duct }}^{0.2163061} \operatorname{Re}_{D h, n z}^{0.577339}{ }^{0.6119346} \operatorname{Pr} \\
& (-0.03209 \phi+0.0169756)+7 n .
\end{aligned}
$$

The valid ranges for Eq. (22) include $6,000 \leq$ $\operatorname{Re}_{D h, \text { duct }} \leq 20,000,6,000 \leq \operatorname{Re}_{D h, n z} \leq 20,000$, $7.2885 \leq \operatorname{Pr} \leq 9.7212,1 \% \leq \phi \leq 5 \%$, and $1 \leq n \leq 4$, respectively.

A comparison between the predicted and computed Nusselt numbers is made and shown in Figure 7. Quite a limited amount of data is found to be outside $\pm 10 \%$ error band. Table 2 shows the comparison between the computed and predicted values of the Nusselt number for different combinations of the variables. Most of the data (i.e., 98.44\%) fall inside $\pm 10 \%$ error band, which may be quite acceptable for any engineering calculation. The Nusselt number obtained from the empirical correlation introduces fewer errors (i.e., $4.37 \%$ ) than that from the CFD solutions. A comparison was made between the Nusselt number obtained from the correlation (Eq. (22)) and CFD solution, as shown in Figure 5(a) and (b), respectively. It was demonstrated that the Nusselt number increased with duct and nozzle Reynolds number. Nevertheless, the predicted and computed values of the Nusselt number are in agreement with each other. Thus, the

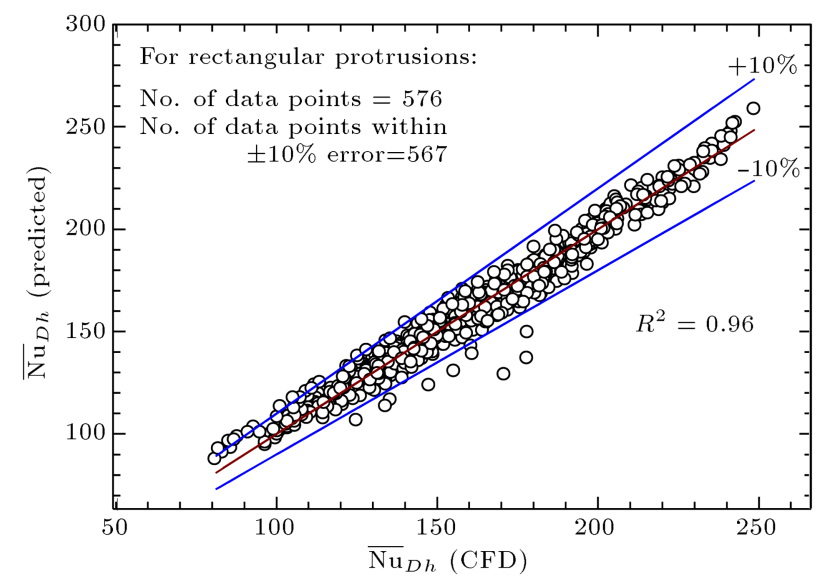

Figure 7. Comparison between the predicted and computed Nusselt numbers.

Table 2. Sample data for the comparison of the computed and predicted Nusselt numbers.

\begin{tabular}{ccccccc}
\hline $\mathbf{R e}_{\boldsymbol{D h}, \boldsymbol{d u c t}}$ & $\mathbf{R e}_{\boldsymbol{D h}, \boldsymbol{n \boldsymbol { z }}}$ & $\mathbf{P r}$ & $\boldsymbol{\phi}$ & $\boldsymbol{n}$ & $\overline{\mathbf{N u}}_{\boldsymbol{C F} \boldsymbol{D}}$ & $\overline{\mathbf{N u}}_{\boldsymbol{C o r}}$ \\
\hline 6,000 & 20,000 & 8.3072 & 3 & 3 & 192.1841 & 189.159 \\
8,000 & 20,000 & 8.3072 & 3 & 3 & 202.913 & 199.9556 \\
10,000 & 20,000 & 8.3072 & 3 & 3 & 213.1146 & 208.8051 \\
12,000 & 20,000 & 8.3072 & 3 & 3 & 220.7246 & 216.3596 \\
16,000 & 20,000 & 8.3072 & 3 & 3 & 230.4051 & 228.9026 \\
20,000 & 20,000 & 8.3072 & 3 & 3 & 233.5806 & 239.1836 \\
6,000 & 20,000 & 8.3072 & 3 & 4 & 194.54 & 196.159 \\
8,000 & 20,000 & 8.3072 & 3 & 4 & 203.5 & 206.9556 \\
10,000 & 20,000 & 8.3072 & 3 & 4 & 215.36 & 215.8051 \\
12,000 & 20,000 & 8.3072 & 3 & 4 & 223.15 & 223.3596 \\
16,000 & 20,000 & 8.3072 & 3 & 4 & 233.214 & 235.9026 \\
20,000 & 20,000 & 8.3072 & 3 & 4 & 240.695 & 246.1836 \\
\hline
\end{tabular}


present correlation may be applied by the practicing engineers to design thermal equipment.

In Figure 5(a) and (b), the effects of duct and nozzle Reynolds numbers on Nusselt number are shown for two volume fractions in order to maintain the clarity of the plots. Since the properties for nanofluid, in general, are altered with the volume fraction, the Prandtl number of the fluid also increases with the increasing volume fraction. Figure 5(a) illustrates a greater heat transfer improvement at a high nanofluid volume fraction than at a low volume fraction. In addition, $\overline{\mathrm{Nu}}_{D h}$ increases monotonously with $\operatorname{Re}_{D h, d u c t}$, as illustrated in Figure 5(b). Good agreement between the CFD and predicted values of $\overline{\mathrm{Nu}}_{D h}$ was established. At a particular $\operatorname{Re}_{D h, n z}, \overline{\mathrm{Nu}}_{D h}$ at a high $\operatorname{Re}_{D h, \text { duct }}$ is more than the value at a low $\operatorname{Re}_{D h, d u c t}$. This is attributed to the strong convection heat transfer because of a high $\operatorname{Re}_{D h, \text { duct }}$. At $\operatorname{Re}_{D h, \text { duct }}=12,000$, the Nusselt numbers have improved by $73.1 \%$ as the nozzle Reynolds number $\left(\operatorname{Re}_{D h, n z}\right)$ changed from 6,000 to 20,000 . Thus, it can be mentioned that $\operatorname{Re}_{D h, d u c t}$ and $\operatorname{Re}_{D h, n z}$ affect the heat transfer significantly.

\subsection{Effect of number of rectangular protrusions on heat transfer rate}

Figure 8 shows the effect of the number of protrusions

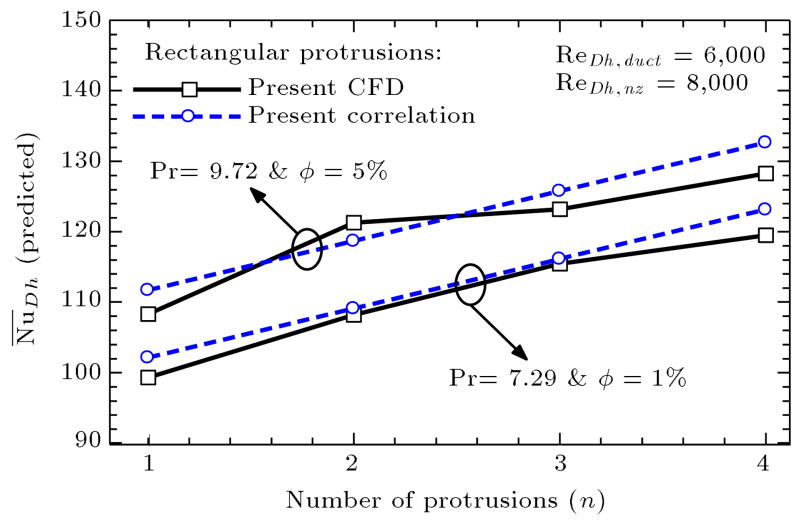

Figure 8. Variation of $\overline{\mathrm{Nu}}$ with $n$.

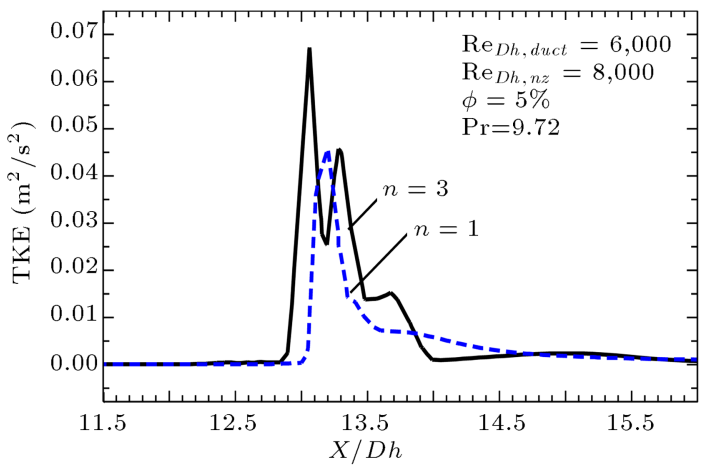

(a) on the heat transfer rate. For a particular volume fraction, e.g., $\phi=1 \%$, one could see a rise in Nusselt number with the number of surface protrusions installed on the heated surface. Due to the surface protrusions, the flow in the rectangular duct becomes more turbulent. Thus, the TKE has increased inside the rectangular duct. For two different volume fractions (i.e., $\phi=5 \%$ and $\phi=1 \%$ ), the evolution of TKE along the centerline of the duct is shown in Figure 9(a) and (b). In both of the cases, a strong variation in TKE has been observed from $X / D h=12.8-14$, showing local peaks in TKE. A higher TKE is expected when more surface protrusions are added to the heated surface. For $n=3$, a higher local peak in TKE than that in the case $n=1$ is seen.

Therefore, when the number of protrusions increases, the TKE also increases, leading to the emergence of a higher local peak. Similar observations have been noticed in both of the cases. Due to the surface protrusions, TKE has increased, resulting in a strong and rigorous mixture of the hot and cold fluid streams. Therefore, the heat from a hot surface dissipates quite easily. The fluid near the hot wall is able to mix thoroughly and strongly with the incoming bulk fluid so as to facilitate the transfer of heat from the hot fluid to cold fluid and, subsequently, a higher amount of heat will be transferred from the heated surface. Therefore, it can be stated that the presence of surface protrusion always augments the transfer of heat from a heated surface, which could be exploited to cool the substrates such as electronic devices for their safe operation and durability. Furthermore, the Nusselt number predicted from the correlation equation is in close agreement with the computed Nusselt number for different surface protrusions. According to Figure 9(b), the TKE increases with the nanofluid volume fraction.

\subsection{Effect of $\phi$ on heat transfer rate}

Figure 10 illustrates the effect of the nanofluid volume fraction on $\overline{\mathrm{Nu}}_{D h}$ for different protrusions. The thermal conductivity of the mixture (i.e., water and

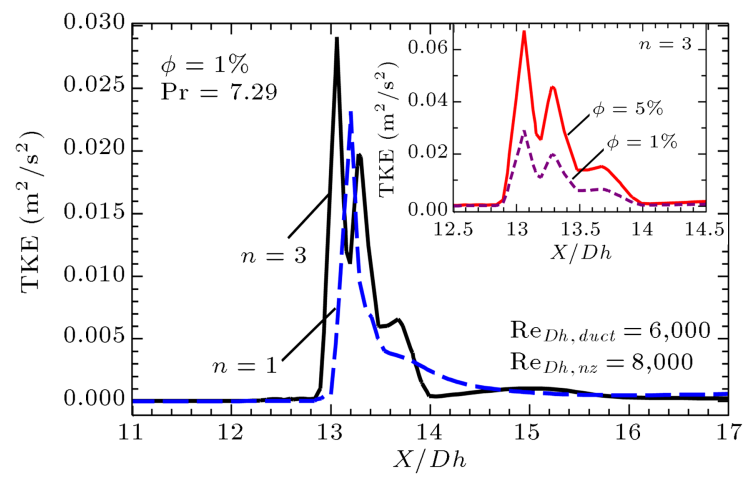

(b)

Figure 9. Variation of centerline TKE along axial direction: (a) $\phi=5 \%, \operatorname{Pr}=9.72$, and (b) $\phi=1 \%, \operatorname{Pr}=7.29$. 


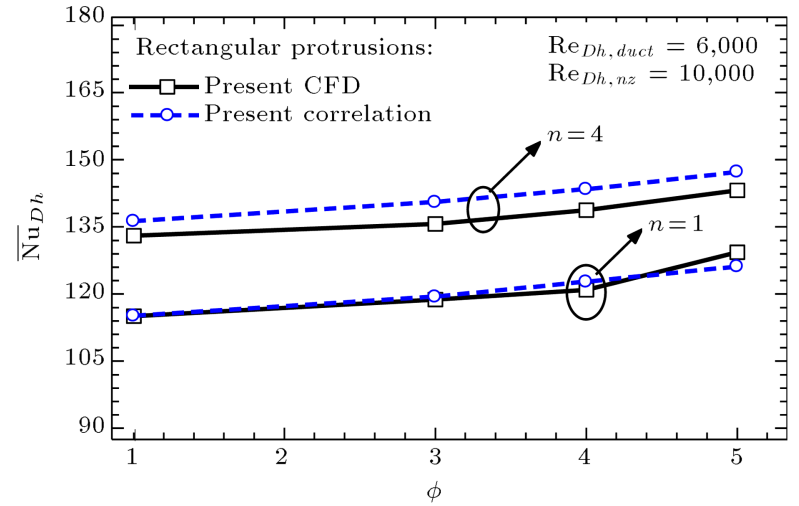

Figure 10. Variation of $\overline{\mathrm{Nu}}$ vs $\phi$.

nanoparticle) is believed to improve with a higher volume fraction. Thus, $\overline{\mathrm{Nu}}_{D h}$ increases with the volume fraction. In Figure 10, the dashed lines show the predicted $\overline{\mathrm{Nu}}_{D h}$, very close to $\overline{\mathrm{Nu}}_{D h}$ from the CFD simulations. For $n=1$ and $n=4$, the error induced in predicting the Nusselt number is about $2.54 \%$ and $2.7 \%$, respectively, which can be considered for any engineering calculation. Moreover, it is seen that the Nusselt number increases significantly with the number of surface protrusions installed on the heated surface.

\section{Conclusions}

Extensive numerical computations were performed to solve the continuity, momentum, energy, and turbulence equations iteratively in a finite volume solver to obtain the Nusselt number for a heated surface. A general empirical correlation was developed in terms of different pertinent parameters. The following conclusions are drawn from this study:

(i) At a constant $\operatorname{Re}_{D h, n z}$ and $\operatorname{Pr}$, the heat transfer increased monotonously with $\operatorname{Re}_{D h, \text { duct }}$. Moreover, the heat transfer rate improved significantly with $\phi$;

(ii) It was also observed that, for a particular $\phi$, the Nusselt number increased with both of the Reynolds numbers (i.e., the duct and the nozzle Reynolds number). It is worth mentioning here that $\phi$ is the most significant parameter in heat transfer improvement, and the Reynolds number is the second best parameter among all such parameters considered in this study;

(iii) The number of protrusions $(n)$ fitted to the hot surface also affects the heat transfer rate. According to the results, a higher TKE is obtained as increases and facilitates a mixture of cold and hot streams to promote heat transfer;

(iv) A general-purpose correlation was developed in terms of different influencing parameters in their wide ranges, which would be handy and useful for practical engineering applications.

\section{Nomenclature}

$\begin{array}{ll}D_{h, d u c t} & \text { Duct hydraulic diameter }(\mathrm{m}) \\ I & \text { Intensity of turbulence } \\ k & \text { Kinetic energy of turbulence }\left(\mathrm{m}^{2} / \mathrm{s}^{2}\right) \\ n & \text { Number of protrusions } \\ \overline{\mathrm{Nu}}_{D h} & \text { Average Nusselt number } \\ \operatorname{Re}_{D h, d u c t} & \text { Reynolds number based on duct } \\ & \text { hydraulic diameter (m) } \\ \operatorname{Re}_{D h, n z} & \text { Reynolds number based on nozzle } \\ \operatorname{Pr}_{t} & \text { hydraulic diameter (m) } \\ \operatorname{Pr}_{\infty} & \text { Turbulent Prandtl number } \\ T_{\infty} & \text { Prandtl number } \\ T_{w} & \text { Isothermal wall temperature }(\mathrm{K}) \\ T_{i n} & \text { Duct inlet temperature }(\mathrm{K}) \\ T_{\text {out }} & \text { Duct outlet temperature }(\mathrm{K}) \\ u_{\text {in }} & \text { Velocity at duct inlet (m/s) } \\ X & \text { Axial direction along the isothermal } \\ & \text { surface (m) }\end{array}$

\section{Greek letters}

$\begin{array}{ll}k & \text { Thermal conductivity }(\mathrm{W} / \mathrm{mK}) \\ \mu & \text { Dynamic viscosity of fluid }(\mathrm{kg} / \mathrm{ms}) \\ \rho & \text { Fluid density }\left(\mathrm{kg} / \mathrm{m}^{3}\right) \\ \omega & \text { Specific dissipation rate }(1 / \mathrm{s}) \\ \phi & \text { Volume fraction }\end{array}$

\section{Subscripts}

$\begin{array}{ll}\text { duct } & \text { Duct } \\ \text { in } & \text { Inlet } \\ n f & \text { Nano fluid } \\ n z & \text { Nozzle } \\ w & \text { Wall } \\ \infty & \text { Ambient }\end{array}$

\section{References}

1. Choi, S.U.S. "Enhancing thermal conductivity of fluids with nanoparticles", ASME International Mechanical Engineering Congress \& Exposition, San Francisco, CA (1995).

2. Lee, S., Choi, S.U.S., Li, S., and Eastman, J.A. "Measuring thermal conductivity of fluid containing oxide nanoparticles", Journal of Heat Transfer, 121, pp. 280-289 (1999). 
3. Eastman, J.A., Choi, S.U.S., Li, S., Yu, W., and Thompson, L.J. "Anomalously increased effective thermal conductivities of ethylene glycol-based nanofluids containing copper nanoparticles", Applied Physics Letters, 78, pp. 718-720 (2001).

4. Karthikeyan, N.R., Philip, J., and Raj, B. "Effect of clustering on the thermal conductivity of nanofluids", Materials Chemistry and Physics, 109, pp. 50-55 (2008).

5. Chandrasekar, M., Suresh, S., and Bose, A.C. "Experimental investigations and theoretical determination of thermal conductivity and viscosity of $\mathrm{Al}_{2} \mathrm{O}_{3} /$ water nanofluid", Experimental Thermal Fluid Science, 34, pp. $210-216$ (2010).

6. Yu, W., Xie, H., Chen, L., and Li, Y. "Enhancement of thermal conductivity of kerosene based $\mathrm{Fe}_{3} \mathrm{O}_{4}$ nanofluids prepared via phase-transfer method", Colloids Surfaces A, 355, pp. 109-113 (2010).

7. Pak, B.C., and Cho, Y.I. "Hydrodynamic and heat transfer study of dispersed fluids with submicron metallic oxide particle", Experimental Heat Transfer, 11, pp. 151-170 (1998).

8. Wen, D., and Ding, Y. "Experimental investigation into convective heat transfer of nanofluid at the entrance region under laminar flow conditions", International Journal of Heat and Mass Transfer, 47, pp. 5181-5188 (2004).

9. Li, Q., Xuan, Y., and Wang J. "Experimental investigation on transport properties of magnetic fluids", Experimental Thermal and Fluid Science, 30, pp. 109116 (2005).

10. Xuan, Y. and Li, Q. "Investigation on convective heat transfer and flow features of nanofluids", Journal of Heat Transfer, 125, pp. 151-155 (2003).

11. Vajjha, R.S., Das, D.K., and Ray, D.R. "Development of new correlations for the Nusselt number and the friction factor under turbulent flow of nanofluids in flat tubes", International Journal of Heat and Mass Transfer, 80, pp. 353-367 (2015).

12. Suresh, S., Venkitaraj, K.P., Selvakumar, P., et al. "Effect of $\mathrm{Al}_{2} \mathrm{O}_{3}-\mathrm{Cu}$ /water hybrid nanofluid in heat transfer", Experimental Thermal and Fluid Science, 38, pp. 54-60 (2012).

13. Xuan, Y. and Roetzel, W. "Conception for heat transfer correlation of nanofluids", International Journal of Heat and Mass Transfer, 43, pp. 3701-3707 (2000).

14. Raji, P., Akhavan-Behabadi, M.A., and Saeedinia, M. "Pressure drop and thermal characteristics of $\mathrm{CuO}-$ base oil nanofluid laminar flow in flattened tubes under constant heat flux", International Communications in Heat and Mass Transfer, 8, pp. 964-971 (2011).

15. Zhang, H., Shao, S., Xu, H., et al. "Heat transfer and flow features of $\mathrm{Al}_{2} \mathrm{O}_{3}$-water nanofluids flowing through a circular microchannel experimental results and correlations", Applied Thermal Engineering, 61, pp. 86-92 (2013).
16. Jafarimoghaddam, A. and Aberoumand, S. "An empirical investigation on $\mathrm{Cu}$ /ethylene glycol nanofluid through a concentric annular tube and proposing a correlation for predicting Nusselt number", Alexandria Engineering Journal, 55, pp. 1047-1052 (2016).

17. Sajadi, A.R. and Kazemi, M.H. "Investigation of turbulent convective heat transfer and pressure drop of $\mathrm{TiO}_{2}$ /water nanofluid in circular tube", International Communications in Heat and Mass Transfer, 38, pp. 1474-1478 (2011).

18. Duangthongsuk, W. and Wongwises, S. "An experimental study on the heat transfer performance and pressure drop of $\mathrm{TiO}_{2}$-water nanofluids flowing under a turbulent flow regime", International Journal of Heat and Mass Transfer, 53, pp. 334-344 (2010).

19. Abbasin Arani, A.A. and Amani, J. "Experimental investigation of diameter effect on heat transfer performance and pressure drop of $\mathrm{TiO}_{2}$-water nanofluid", Experimental Thermal and Fluid Science, 44, pp. 520533 (2013).

20. Anoop, K.B., Sundararajan, T., and Das, S.K. "Effect of particle size on the convective heat transfer in nanofluid in the developing region", International Journal of Heat and Mass Transfer, 52, pp. 2189-2195 (2009).

21. Sheikholeslami, M., Gorji-Bandpy, M., and Ganji, D.D. "Natural convection in a nanofluid filled concentric annulus between an outer square cylinder and an inner elliptic cylinder", Scientia Iranica B, 20, pp. 1241-1253 (2013).

22. Nemati, H., Farhadi, M., Sedighi, K., et al. "Magnetic field effects on natural convection flow of nanofluid in a rectangular cavity using lattice Boltzmann model", Scientia Iranica B, 20, pp. 1241-1253 (2013).

23. Khorasanizadeh, H., Amani, J., and Nikfar, M. "Numerical investigation of $\mathrm{Cu}$-water nanofluid natural convection and entropy generation within a cavity with an embedded conductive baffle", Scientia Iranica F, 19, pp. 1996-2003 (2012).

24. Wei, W., Cai, J., Hu, X., Han, Q., et al. "Fractal analysis of the effect of particle aggregation distribution on thermal conductivity of nanofluids", Physics Letters A, 380, pp. 2953-2956 (2016).

25. Siavashi, M., Yousofvand, R., and Rezanejad, S. "Nanofluid and porous fins effect on natural convection and entropy generation of flow inside a cavity", Advanced Powder Technology, 29, pp. 142-156 (2018).

26. Mukherjee, A., Rout, S., and Barik, A.K. "Heat transfer and entropy generation analysis of protruded surface in presence of a cross-flow jet using $\mathrm{Al}_{2} \mathrm{O}_{3}$ water nanofluid", Thermal Science and Engineering Progress, 5, pp. 327-338 (2018).

27. Bianco, V., Chiacchio, F., Manca, O., et al. "Numerical investigation of nanofluids forced convection in circular tubes", Applied Thermal Engineering, 29, pp. 3632-3642 (2009). 
28. Maiga, S.E.B., Palm, S.J., Nguyen, C.T., et al. "Heat transfer enhancement in turbulent tube flow using $\mathrm{Al}_{2} \mathrm{O}_{3}$ nanoparticle suspension", International Journal of Numerical Methods for Heat \& Fluid Flow, 16, pp. 275-292 (2006).

29. Akbarinia, A. and Behzadmehr, A. "Numerical study of laminar mixed convection of nanofluid in horizontal curved tubes", Applied Thermal Engineering, 27, pp. 1327-1337 (2007).

30. Wang, X., Xu, X., and Choi, S.U.S. "Thermal conductivity of nanoparticle-fluid mixture", Journal of Thermophysics and Heat Transfer, 13, pp. 474-480 (1999).

31. Lee, S., Choi, S.U.S., Li, S., et al. "Measuring thermal conductivity of fluids containing oxide nanoparticles", Journal Heat Transfer, 121, pp. 280-289 (1999).

32. Barik, A.K., Dash, S.K., and Guha, A. "Experimental and numerical investigation of air entrainment into an infrared suppression device", Applied Thermal Engineering, 75, pp. 33-44 (2015).

33. Boertza, H., Baars, A., Cieslinskib, J.T. et al. "Numerical study of turbulent flow and heat transfer of nanofluids in pipes", Heat Transfer Engineering, 39, pp. 241-251 (2018). Doi:/10.1080/01457632.2017.1295739

34. Mentor, F.R. "Two-equation eddy-viscosity turbulence models for engineering applications", AIAA Journal, 32, pp. 1598-1605 (1994).

35. Barik, A.K., Rout, S., and Mukherjee, A. "Numerical investigation of heat transfer enhancement from protruded surface by cross-flow jet using $\mathrm{Al}_{2} \mathrm{O}_{3}$-water nanofluid", International Journal of Heat and Mass Transfer, 101, pp. 550-561 (2016).

36. Launder, B.E. and Spalding, D.B. "The numerical computation of turbulent flows", Computer Methods in Applied Mechanics and Engineering, 3, pp. 28692879 (1974).

37. Zuckerman, N. and Lior, N. "Impingement heat transfer: correlations and numerical modeling", Journal of Heat Transfer, 127, pp. 544-552 (2005).

38. Barik, A.K., Mukherjee, A., and Patro, P. "Heat transfer enhancement from a small rectangular channel with different surface protrusions by a turbulent cross flow jet", International Journal of Thermal Sciences, 98, pp. 32-41 (2015).

39. Bouhalleb, M. and Abbassi, H. "Numerical investigation of heat transfer by $\mathrm{CuO}$-water nanofluid in rectangular enclosures", Heat Transfer Engineering, 37, pp. 13-23 (2016).

40. Sun, B., Qu, Y., and Yang, D. "Heat transfer of single impinging jet with $\mathrm{Cu}$ nanofluids", Applied Thermal Engineering, 102, pp. 701-707 (2016).

\section{Biographies}

Swetapdama Rout received her MTech degree in Mechanical Engineering from College of Engineering and Technology (CET), Bhubaneswar, India in 2016. Presently, she is working as a Project Fellow on a DST sponsored project at CET, Bhubaneswar. Her research interests include heat transfer augmentation, turbulence modeling, and electronics cooling.

Arnab Mukherjee received his MTech degree from College of Engineering and Technology (CET), Bhubaneswar, India in 2016. He is now working as a Project Fellow at National Institute of Technology, Rourkela, India. His research interests include the design and development of IRS devices, computational fluid dynamics and turbulence modeling, etc.

Ashok K. Barik received his $\mathrm{PhD}$ from the Indian Institute of Technology, Kharagpur, India in 2015. $\mathrm{He}$ is working as an Assistant Professor at the Department of Mechanical Engineering at the College of Engineering and Technology, Bhubaneswar, India. He is a fellow and life member of International Society for Research and Development (ISRD), UK. He has published 13 international journal papers and several conference papers. His active areas of research are heat transfer augmentation, forced convection, nanofluids, CFD, multi-phase flows, and nano and micro transport phenomena. 